\title{
Ice shelf stability and the brittle-ductile transition
}

\author{
Bradley Paul Lipovsky \\ Department of Earth and Planetary Sciences, Harvard University \\ brad_lipovsky@ harvard.edu
}

\begin{abstract}
Fracturing processes limit the ability of floating ice shelves to stabilize marine ice sheets. Ice shelf fracturing may occur as either horizontally propagating rifts or vertically propagating and possibly water-filled crevasses. Here, I argue that ice shelves are most susceptible to brittle fracture when their thickness is less than the brittle-ductile transition thickness $H_{*}$, defined as the depth at which the overburden pressure equals the local yield strength in tension. A fracture mechanical analysis, compared with time-lapse imagery and thickness maps demonstrate the ice dynamical role of the brittle-ductile transition. These findings suggest the existence of a calving-thinning instability whereby thinning-induced brittleness increases calving rates and reduces buttressing.
\end{abstract}

Global mean sea level rise is expected to accelerate by the year 2100. Although the likely range for sea level rise rate by the year 2100 is 0.8 to $1.6 \mathrm{~cm} / \mathrm{a}(1)$, a physically plausible set of models suggest that this could be an underestimate due to ice dynamical instabilities in Antarctica (2). Sea level rise rates result from such instability may be as large as $3 \mathrm{~cm} / \mathrm{a}$ by 2100 and $6 \mathrm{~cm} / \mathrm{a}$ by around 2150 . The spread in these estimates has profound planning implications (1), therefore motivating the careful study of the underlying physical processes. Rapid sea level rise scenarios generally involve the widespread fracturing, calving, and break-up of the ice shelves (3) and an ensuing acceleration of grounded ice (4). Given this importance, the 
representation of ice shelf fracturing and calving in ice sheet models has received considerable attention. Alley and others introduced a parameterization based on geometric and mass balance considerations (5). Levermann and others incorporated principal strain paths to calculate ice fronts $(6)$, consistent with fracture mechanical approaches (7). Damage mechanics has been employed to consider widespread deformation (8). Other efforts have attempted to extend theories of vertical crevasse propagation to ice shelves (9-11) and to include the effect of ice cliff failure $(2,12)$. Although these approaches have facilitated the study of marine ice sheet dynamics, one may still raise the concern that none account for the unique physics associated with the dominant mode of ice shelf calving: the horizontal propagation of through-cutting fractures called rifts (13). Here, I present a fracture mechanical analysis of the life cycle and dynamical importance of ice shelf rifts and of ice shelf fracture in general. I argue that ice shelf fracturing and calving are fundamentally controlled by the ice shelf brittle-ductile transition.

Ice shelf calving involves both brittle and ductile behaviors (13), and for this reason neither entirely-brittle nor entirely-ductile rheologies are able to completely explain fundamental calving behaviors. Force balance and the use of linear elastic fracture mechanics, as further described in the Supplementary Materials, give rise to the brittle fracture criterion (14)

$$
\tau=\rho g s / 2 \equiv \rho^{\prime} g H
$$

$\tau$ is the remote deviatoric extensional stress in the direction normal to the rift, $\rho$ is the density of ice $g$ is acceleration due to gravity, and $s$ is the ice shelf height above the water line, and $H$ is the ice thickness. The main limitation of Equation 1 is that it cannot explain the widely observed tendency for rifts to arrest in suture zones.

Suture zones are provenance boundaries within an ice shelf (7). These boundaries are commonly observed to act as barriers to rift propagation $(7,15-17)$. Several studies have invoked fracture toughness variations in ice shelves to explain this stabilization in suture zones $(7,17)$. 
A. Ice shelf with thick ductile ice

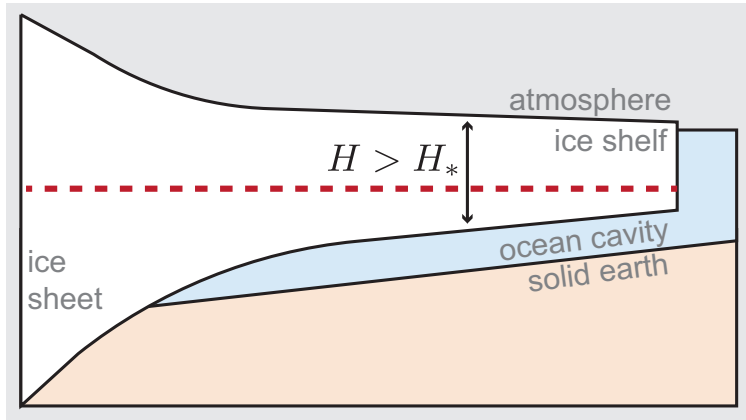

C. Rift propagation in low strength marine ice

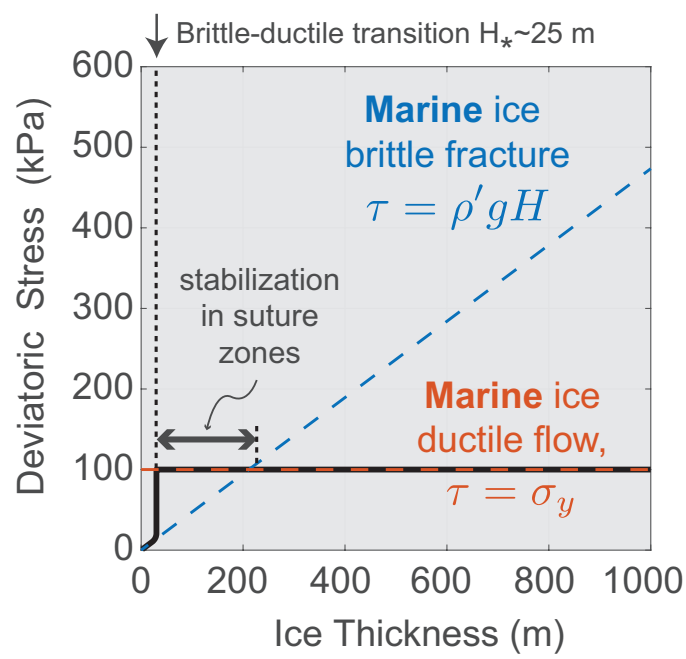

B. Ice Shelf with a thin brittle tongue

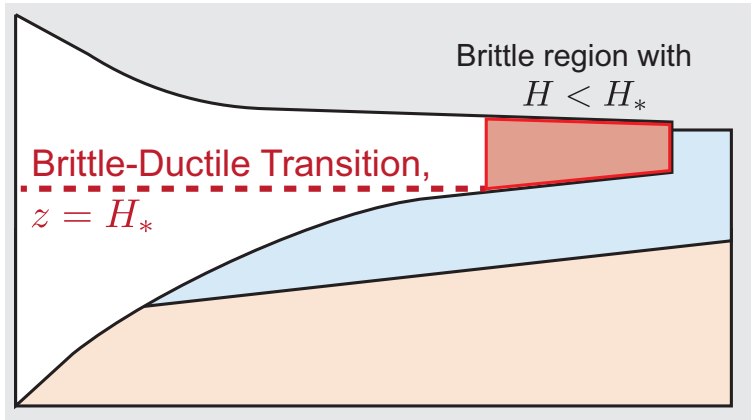

D. Rift propagation in high strength meteoric ice

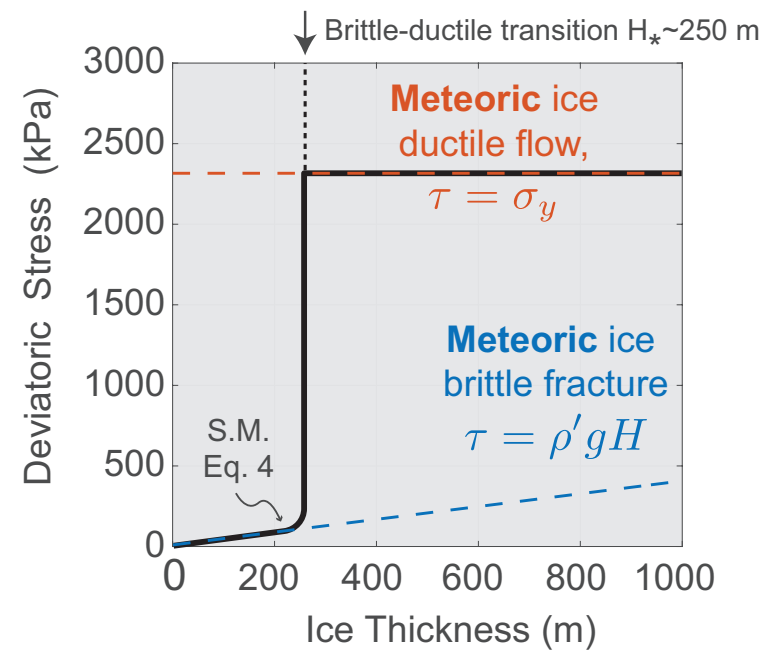

Figure 1: A. Ductile flow inhibits brittle fracture in ice thicker than the brittle-ductile transition thickness $H_{*} \approx 250 \mathrm{~m}$. B. Ice shelves thinner than the brittle-ductile transition thickness are more likely to undergo brittle fracturing. C. and D. show the rift normal deviatoric stress at failure for marine and meteoric ice, respectively. $H_{*}$ is much smaller for marine ice than for meteoric ice. 

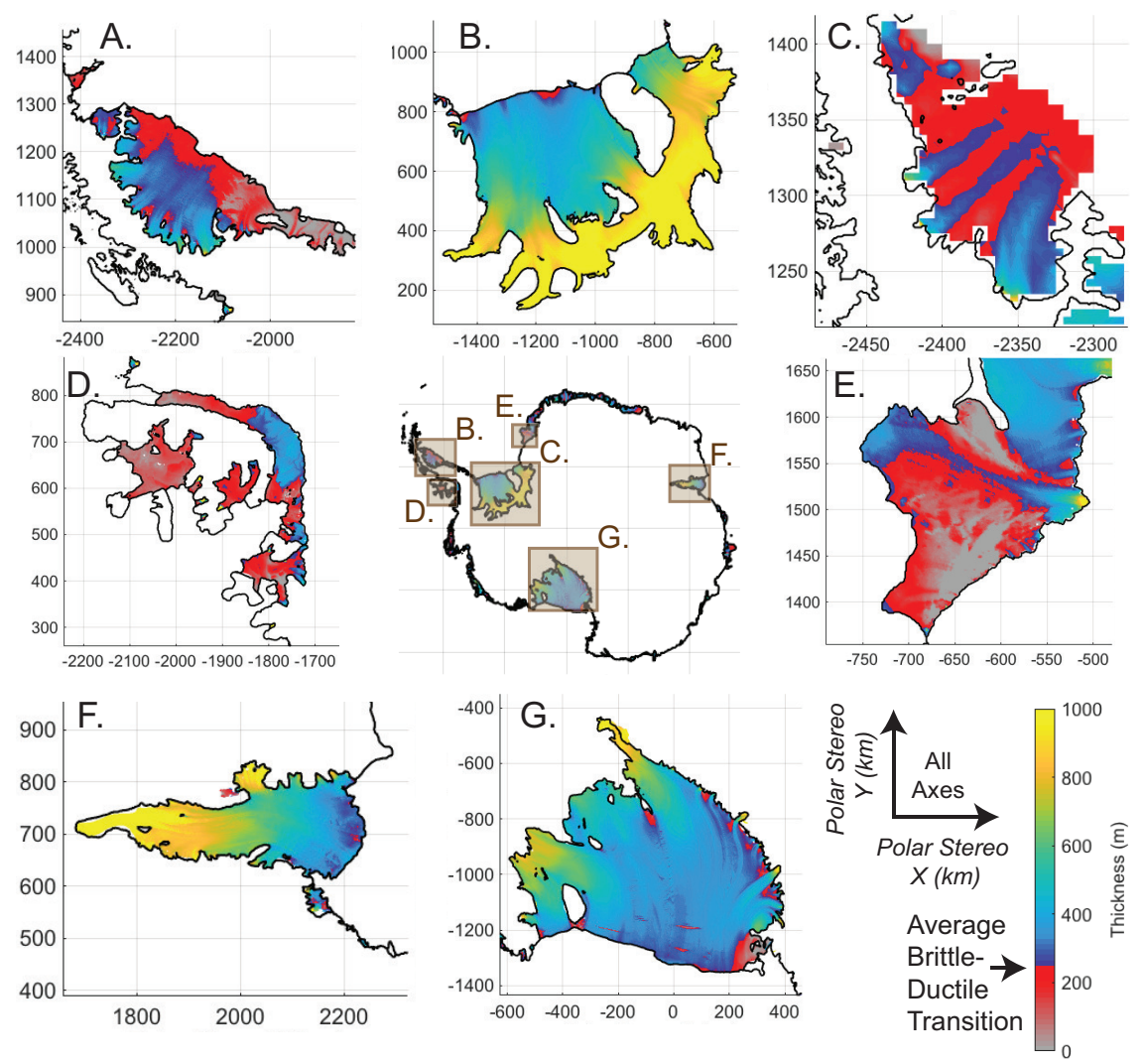

Figure 2: Ice thicknesses in several ice shelves around Antarctica. Shades of red denote thickness less than the brittle-ductile transition thickness. Inset: Overview Map. Subplots show ice shelves: A. Larsen C, B. Ronne-Filchner, C. Larsen B, D. Wilkins/King George VI, E. Brunt/Stancomb-Wills, F. Amery, G. Ross. Datasets described in the supplementary materials. 
Yet this explanation is problematic because, as discussed in the Supplementary Material, typical fracture toughness values of ice are so small so as to be negligible. This is reflected by the absence of the fracture toughness in Equation 2. Mechanical testing on ice shelf specimens (18) further argue against a role of fracture toughness during the arrest of rift propagation. These tests show only minor variations in fracture toughness (18), and therefore argue against a role of fracture toughness heterogeneity in controlling rift propagation. A resolution to this apparent discrepancy is that ice is not always brittle.

Ice has a complex material response wherein elastic behavior initially transitions to a strain rate hardening rheology before ultimately exhibiting strain rate softening at large strains (19). Here, I treat ice as an elastic-perfectly plastic solid, whereby rift propagation in the ductile regime occurs whenever a strength of materials yield criterion is satisfied. Consistent with the goals of my analysis, this approximation is expected to provide a satisfactory description of the onset of ductility. In a simplified model (Figure 1a), ductile flow occurs whenever the deviatoric rift normal stress exceeds the yield stress,

$$
\tau=\sigma_{y}
$$

The yield strength of ice in tension is on the order of $\sigma_{y}=1-3 \mathrm{MPa}$ for columnar freshwater ice $(19,20)$ and on the order of $\sigma_{y}=0.1-0.8 \mathrm{MPa}$ for marine ice $(21)$. The yield strength in tension is distinct from the yield strength in compression (19) familiar, for example, within the plastic ice sheet approximation. Taken by itself, Equation 2 is also inadequate because it cannot account for observations which show that rifts may propagate at fast rates at least equal to tens of kilometers per week, as discussed later. Ductile flow, in contrast, is a much slower process controlled by dislocation kinetics (19). Observations therefore demand an explanation of the ice shelf brittle-ductile transition.

Ice exhibits a brittle-ductile transition when the energy required to propagate fractures is 
equal to the energy required to induce flow (19). On either side of this energy transition, whichever process requires less energy will be the process that occurs in nature. I first focus on the effect of confining pressure and later discuss the role of salinity. The brittle-ductile transition for materials under an overburden pressure $\rho g H$ occurs at a depth (22)

$$
H_{*} \equiv \sigma_{y} /(\rho g)
$$

Below this depth the overburden pressure exceeds the yield strength of ice in tension $\sigma_{y}$. I later discuss glaciological controls on $\sigma_{y}$. Here, I take $H_{*}=250 \mathrm{~m}$ as a typical value which corresponds to $\sigma_{y}=2.3 \mathrm{MPa}$, a representative value for freshwater ice at $-20^{\circ} \mathrm{C}(20)$. The ice shelf brittle-ductile transition is schematically illustrated in Figure 1a and b.

Maps showing ice shelf thicknesses are presented in the panels of Figure 2, where an approximate brittle-ductile transition thickness $H_{*}$ is represented by the red-to-blue contour. Note that these figures do not capture shallowing of the brittle-ductile transition due to marine ice accretion, as discussed later. Figure 2 shows that several ice shelves that have recently experienced large calving events (Larsen C), collapsed (Wilkins), and those with rapidly propagating rifts (Brunt) have significant regions with thin brittle ice $H<H_{*}(17,23,24)$.

To more rigorously evaluate the relationship between ice thickness, rifting, and the brittleductile transition, I update a previously published catalog of ice shelf rifts (25) using newer imagery to search for previously identified rifts which have recently experienced calving events. For each rift that has not yet calved, I calculate the ice shelf thickness at the rift tip (see Supplementary Materials). The results are plotted in Figure 3a. I find that most ice shelf rifts arrest in ice with median thickness $279 \mathrm{~m}$, whereas rifts that calved during the observation period occur in ice with median thickness $226 \mathrm{~m}$. I interpret these two depths as defining a brittle-ductile transition zone.

A snapshot of present-day ice shelf thickness puts the brittle-ductile transition in a broader 
ice dynamical context (Figure 3b). The present-day ice shelf thickness distribution has a single peak at $392 \mathrm{~m}$ which I interpret as representing a balance between calving and thinning. Ice shelf regions thicker than this median thickness are fewer because flow preferentially stretches thick ice. Ice shelf regions thinner than this median thickness are fewer because calving preferentially removes thin brittle ice. This latter interpretation is supported by the overlap between the distribution of calved rift thicknesses (median \pm 1 interquartile range, or "Middle $50 \%$ " $=$ 169 to $283 \mathrm{~m}$ ) and the median ice shelf thickness.

A combined rift propagation criterion that describes both brittle and ductile behavior is,

$$
\tau= \begin{cases}\rho^{\prime} g H & H<H_{*} \\ \sigma_{y} & H \geq H_{*}\end{cases}
$$

This brittle-ductile propagation criterion explains three prominent observations of rift propagation behavior: 1) the stabilization of rifts in suture zones, 2) the wide range of observed rift propagation rates, and 3) a previous observed scaling between calving and strain rate.

The brittle-ductile transition provides a plausible mechanism for the stabilization of rifts in ice shelf suture zones. Observations show that ice shelf suture zones infill with accreted marine ice $(15,16)$. Marine ice has a much lower yield strength $\sigma_{y}$ than ice formed from fresh water (21). Suture zones therefore have an abnormally shallow brittle-ductile transition. As shown in Figure 1c, this low yield strength requires higher absolute deviatoric stresses to cause rift propagation versus the brittle fracture criterion, therefore explaining the tendency of suture zones to stabilize rift propagation.

Suture zones do not always halt rift propagation. Under the proposed calving law (Equation 4), propagation will occur in the ductile regime whenever the deviatoric extensional stress exceeds the tensional yield strength. This condition explains the observation by King (26) of rift propagation along a suture zone. In this case, propagation is explained by the existence of elevated extensional deviatoric stresses normal to the suture zone. Rifts may also halt their 

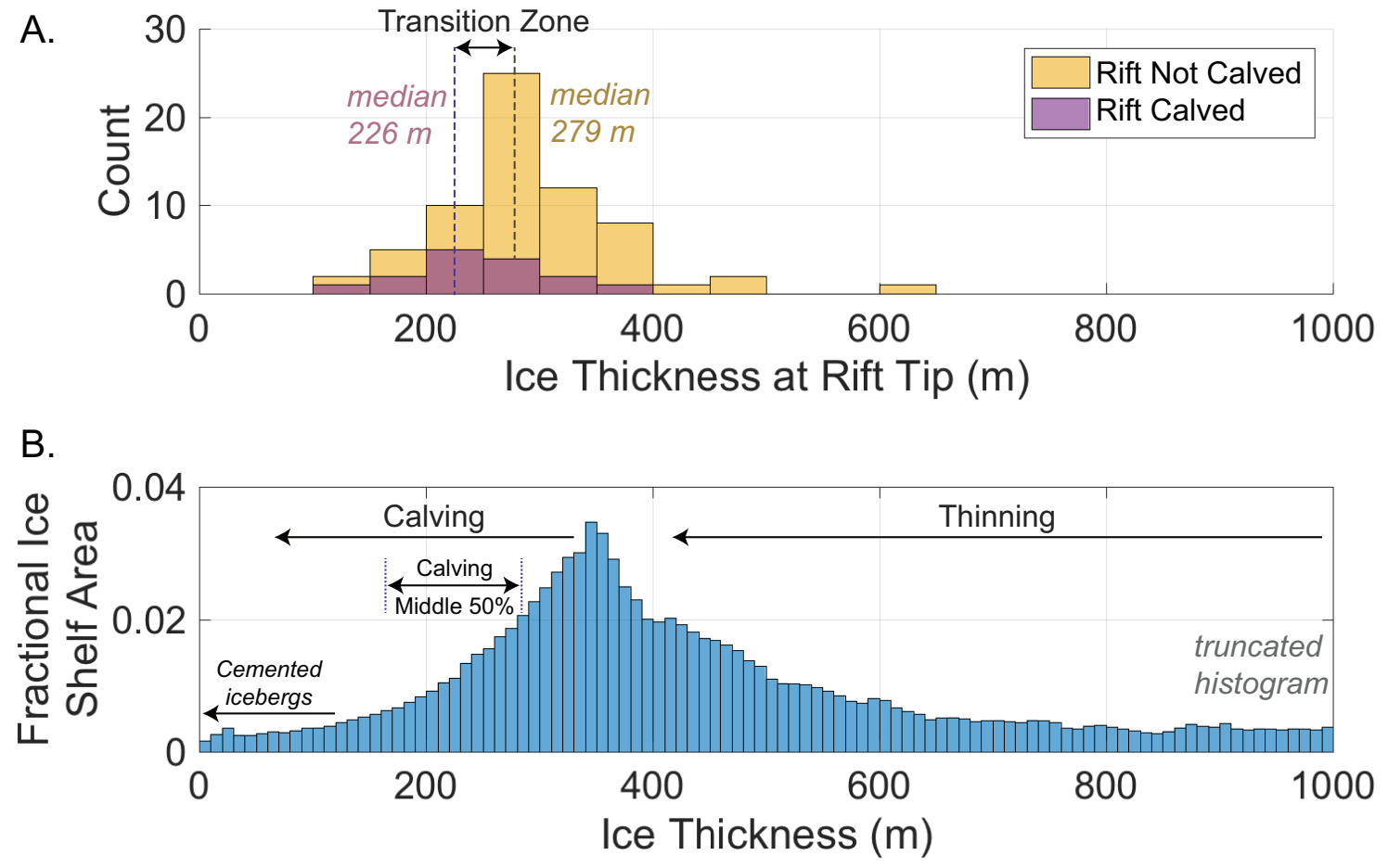

Figure 3: A. Ice shelf rifts tend to arrest their propagation in ice with thickness $279 \mathrm{~m}$ (median) but tend to propagate until calving in ice with thickness $226 \mathrm{~m}$. B. The most common ice shelf thickness (median $392 \mathrm{~m}$ ) occurs as a balance between thinning of originally deep grounded ice and brittle calving. 
propagation due to stresses sufficiently low so as to not satisfy the brittle yield criterion. Prior to its disintegration, the Larsen B Ice Shelf exhibited extensive thin regions (Figure 2c). Within the context of the proposed fracture law (Equation 4), this thinning provides a plausible mechanism for disintegration. Although the triggers for the exact timing of this event, and of ice shelf fracturing in general, remain not completely understood, ocean wave-induced triggering provides a plausible mechanism $(27,28)$.

The brittle-ductile transition also offers insights into the wide range of observed rift propagation rates. Slow rift propagation occurs at speeds of several $\mathrm{km} / \mathrm{a}$ and is the most commonly observed style of rifting in Antarctica (25). Slow propagation is consistent with the observation that most not-yet-calved rifts have propagated into thick, ductile ice (i.e., Figure 3). Fractures that terminate in a ductile region are expected to develop extensive regions of plastic deformation near the fracture tip (19). These regions may allow for the accumulation of residual stresses and therefore set the stage for subcritical crack growth (29).

Fast propagation, in contrast, occurs rates at least equal tens of kilometers per week, a lower bound because observations are typically limited to approximately weekly satellite flyover times $(17,23,24)$. Sparse in situ observations suggest that propagation speeds may be much faster, with one lower bound on the order of $\mathrm{km} / \mathrm{min}$ (23). Because fast propagation occurs much more quickly than typical ice Maxwell times (19), its occurrence suggests the presence of ductile conditions.

If rifts do not halt their propagation in suture zones or elsewhere, then a calving event will create a new iceberg. The transition to brittleness suggests a scaling argument for calving rate whereby the approximate calving rate scales as the amount of time required to regenerate a thin, brittle frontal region. This time is approximately

$$
t \sim\left(H-H_{*}\right) /(\partial H / \partial t) .
$$




\begin{tabular}{|c|c|c|c|}
\hline Ice Shelf & Thickness, $H(\mathrm{~m})$ & $\partial H / \partial t(\mathrm{~m} / \mathrm{a})$ & Brittle instability time scale(a) \\
\hline Riiser-Larsen & 360 & +0.31 & n/a \\
Filchner & 420 & -0.13 & 1300 \\
Ronne & 330 & -0.15 & 533 \\
Getz & 500 & -2.2 & 114 \\
Pine Island & 430 & -5.8 & 31 \\
Thwaites & 400 & -6.7 & 22 \\
\hline
\end{tabular}

Table 1: Approximate time until brittle conditions occur at several ice fronts.

This scaling relation is consistent with previously noted empirical correlations between strain rate and calving rate $(5,6)$.

Ice shelf thinning may potentially destabilize fractures by inducing the change from ductile flow to brittle fracture. A potential instability may occur whereby a thinning ice shelf first becomes brittle and as a result experiences an increase in calving. Upon this increase in calving, buttressing support is lost which causes further thinning, and so on. In this way, calving and thinning are expected to be coupled processes.

In order to assess the likelihood of this calving-thinning instability, I calculate how long it will take to thin ice to the thickness $H=H_{*}$ (Equation 5; data described in the Supplementary Materials). My calculations are presented in Table 1. The most stable ice shelves are those experiencing net thickening such as the Riiser-Larsen. Any thickening ice shelf is not susceptible to the above-described calving-thinning instability. The Ronne and Filchner ice shelves both have relatively long times until brittle instability due to their slow thinning rates. If present thinning rates persist, ice shelves in the Amundsen sea sector appear susceptible to instability within the next few decades. Several ice shelves including Abbot, Shackleton, and George VI, have average thicknesses near or below $250 \mathrm{~m}$, although these shelves each have large regions of longitudinal deviatoric compression so that Equation 2 is seldom satisfied there.

Vertical hydraulic fracture propagation due to the formation of surface melt has been linked to the collapse of the Larsen B ice shelf in 2002 (3). Previous analyses of the fracture me- 
chanics of vertical hydraulic fracture propagation have assumed either entirely-brittle $(10,30)$ or entirely-ductile (3) rheologies. The arguments set forth here, however, suggest that glaciological conditions determine which regime is applicable. Figure 2), for example, shows that hydraulic fracture propagation entirely in the brittle regime is not currently possible on most Antarctic ice shelves. The pre-collapse Larsen B ice shelf, however, was particularly susceptible to brittle hydraulic fracture propagation given its low ice thicknesses (Figure 2c). This suggests that low ice thickness is a necessary condition for ice shelf disintegration.

The importance of the ice yield strength in tension for ice shelf stability suggests the importance of detailed knowledge of the in situ yield strength of actual ice shelf ice. Despite this, and unlike fracture toughness measurements (18), I am not aware of any in situ tensional yield strength measurements from ice shelves or of accreted basal marine ice (the measurements referenced above were from sea ice). Particular effort should be placed on the role of confining pressure (22). It is known that ice yield strength in tension is mostly a function of grain size ( $\sim 30 \%$ variations) and saltiness (greater than order-of-magnitude variations) but is relatively insensitive to variations in temperature and strain rate $(19,20)$. It is currently less well known how observed variations in marine ice permeability (31), bulk sample size (20), or memory effects (19) alter ice shelf strength. Additional modelling, geophysical, ice core, and field studies are needed to understand how laboratory measurements relate to actual ice shelves. Future ice shelf stability is underlain by the brittle-ductile transition.

\section{Acknowledgements}

This manuscript benefited from discussions with Hilmar Gudmundsson, Jan De Rydt, Doug MacAyeal, Christina Hulbe, Mathieu Morlighem, and Brent Minchew. This work was supported by a fellowship in the Department of Earth and Planetary Sciences at Harvard University. 


\section{References}

1. Intergovernmental Panel On Climate Change, Global Warming Of 1.5 C (2018), chap. 3: Impacts of $1.5^{\circ} \mathrm{C}$ global warming on natural and human systems, p. 33 .

2. R. M. DeConto, D. Pollard, Nature 531, 591 (2016).

3. A. F. Banwell, D. R. MacAyeal, O. V. Sergienko, Geophysical Research Letters 40, 5872 (2013).

4. E. Rignot, et al., Geophysical Research Letters 31 (2004).

5. R. B. Alley, et al., Science 322, 1344 (2008).

6. A. Levermann, et al., The Cryosphere 6, 273 (2012).

7. C. L. Hulbe, C. LeDoux, K. Cruikshank, Journal of Glaciology 56, 459 (2010).

8. C. Borstad, E. Rignot, J. Mouginot, M. Schodlok, The Cryosphere 7 (2013).

9. C. Van der Veen, Cold Regions Science and Technology 27, 31 (1998).

10. F. Nick, C. J. Van der Veen, A. Vieli, D. Benn, Journal of Glaciology 56, 781 (2010).

11. H. Yu, E. Rignot, M. Morlighem, H. Seroussi, The Cryosphere 11, 1283 (2017).

12. J. Bassis, C. Walker, Proc. R. Soc. A p. rspa20110422 (2011).

13. D. I. Benn, C. R. Warren, R. H. Mottram, Earth-Science Reviews 82, 143 (2007).

14. H. Tada, P. C. Paris, G. R. Irwin, Handbook, Del Research Corporation (1973).

15. D. McGrath, et al., Journal of Geophysical Research: Earth Surface 119, 588 (2014). 
16. B. Kulessa, D. Jansen, A. J. Luckman, E. C. King, P. R. Sammonds, Nature communications 5, 3707 (2014).

17. C. Borstad, D. McGrath, A. Pope, Geophysical Research Letters 44, 4186 (2017).

18. M. Rist, P. Sammonds, H. Oerter, C. Doake, Journal of Geophysical Research: Solid Earth 107 (2002).

19. E. M. Schulson, P. Duval, et al., Creep and fracture of ice, vol. 1 (Cambridge University Press Cambridge, 2009).

20. J. Petrovic, Journal of materials science 38, 1 (2003).

21. J. Richter-Menge, K. Jones, Journal of Glaciology 39, 609 (1993).

22. A. M. Rubin, Journal of Geophysical Research: Solid Earth 98, 15919 (1993).

23. A. F. Banwell, et al., Annals of Glaciology pp. 1-10 (2017).

24. J. De Rydt, H. Gudmundsson, T. Nagler, J. Wuite, E. C. King, The Cryosphere 12, 505 (2018).

25. C. Walker, J. Bassis, H. Fricker, R. Czerwinski, Journal of Geophysical Research: Earth Surface 118, 2354 (2013).

26. E. C. King, J. De Rydt, G. H. Gudmundsson, The Cryosphere Discuss (2018).

27. B. P. Lipovsky, Journal of Geophysical Research: Oceans (2018).

28. R. A. Massom, et al., Nature p. 1 (2018).

29. J. Weiss, Journal of Glaciology 50, 109 (2004).

30. T. Scambos, et al., Earth and Planetary Science Letters 280, 51 (2009). 
31. M. Craven, I. Allison, H. A. Fricker, R. Warner, Journal of Glaciology 55, 717 (2009). 


\section{Supplementary Materials for Ice shelf stability and the brittle-ductile transition}

\section{Contents}

1 Fracture mechanical analysis 2

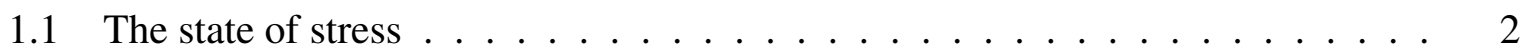

1.2 Brittle fracture mechanics . . . . . . . . . . . . . . . . 3

1.3 Lateral variations in ice shelf properties $\ldots \ldots \ldots \ldots \ldots$

1.4 Transition to ductile yielding $\ldots \ldots \ldots \ldots \ldots \ldots \ldots$

$\begin{array}{lll}2 & \text { Analysis of published geophysical data sets } & 7\end{array}$

\section{List of Figures}

1 Schematic representation of the ice shelf force balance near a rift. . . . . . . . 2

\section{Additional Files}

Data.txt is a file containing the rift database. It contains rows that correspond to rifting style, ice shelf name, rift name, rift length $(\mathrm{km})$, latitude, longitude, imagery source, ice thickness at arrest point according to BEDMAP2, rift number, and the ice thickness at the arrest point according to the Chuter and Bamber ice thickness map. 


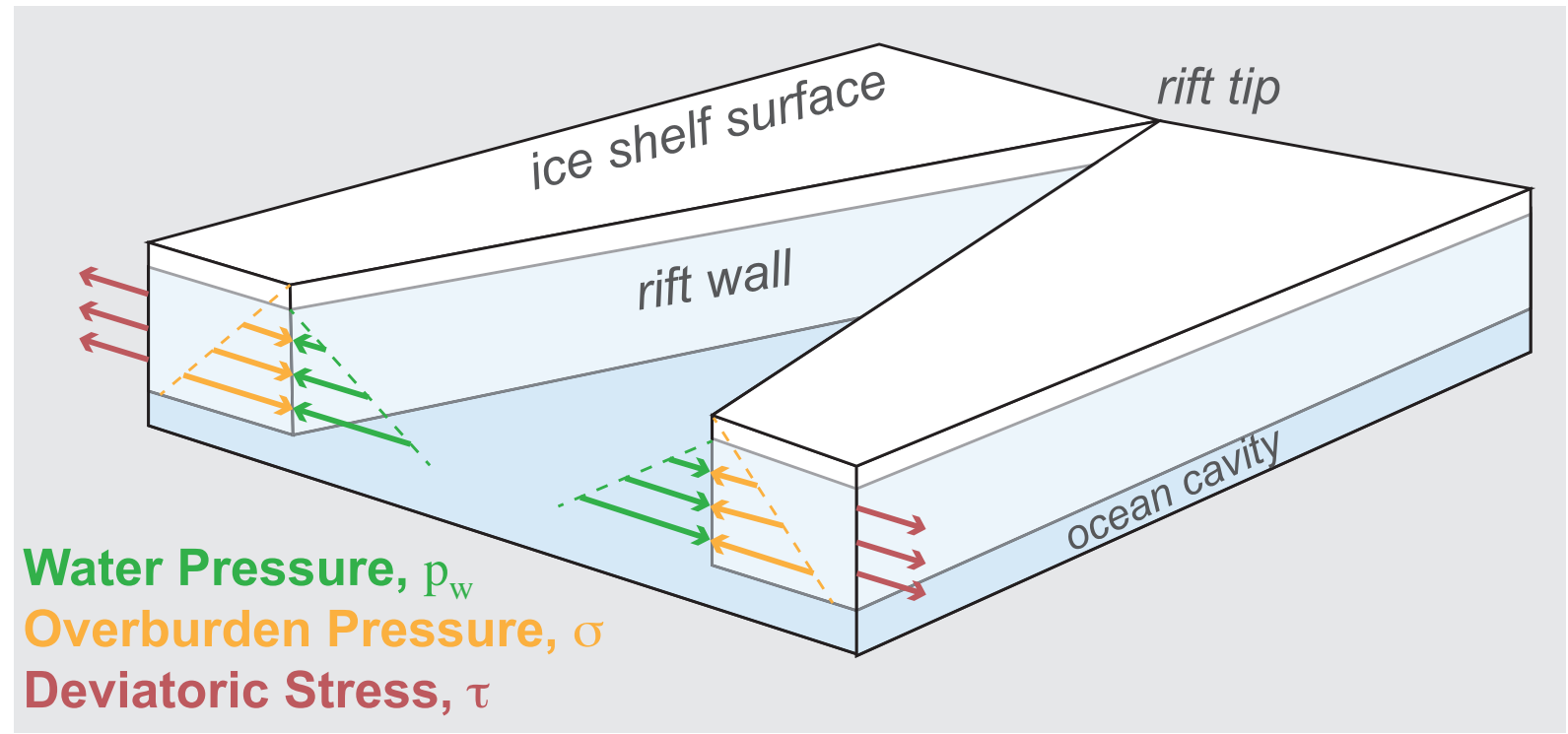

Figure 1: Schematic representation of the ice shelf force balance near a rift.

\section{Fracture mechanical analysis}

\subsection{The state of stress}

Here I describe the state of stress near an ice shelf rift and then relate this state of stress to a fracture criterion. The rift walls are assumed be vertical and to have a normal vector on the $x$-axis. The depth-dependent total (Cauchy) stress acting normal to the rift walls is then the stress component $\sigma_{x}=p+\tau_{x}$ where $\tau_{x}$ is the corresponding deviatoric stress component and $p$ is the pressure. Standard assumptions (1) of incompressibility and zero vertical shear then give,

$$
\sigma_{x}=2 \tau_{x}-\rho g(s-z)
$$

where $s(x)$ is the ice shelf height above the water line, $z$ is taken to be positive upwards, and $\rho$ is the density of ice. I recall that the stress $\sigma_{x}$ takes both signs with positive indicating tension.

I now consider a rift in the ice shelf as shown in Figure 1. The effective pressure is found by subtracting the hydrostatic water pressure $p_{w}(z)$ from total horizontal stress. As no other stress 
components are referenced I drop the subscripted $x$ in the following and write,

$$
\sigma(z)-p_{w}(z) \equiv-\rho g(s-z)-\rho_{w} g z_{*}+2 \tau_{x}
$$

where $\rho_{w}$ is the density of water and the notation $z_{*}$ indicates $z_{*}=0$ if $z>0$ and $z_{*}=z$ if $z \leq 0$. With this notation $-p_{w}$ is always positive indicating that it acts to open the rift.

\subsection{Brittle fracture mechanics}

Fractures, including ice shelf rifts, are expected to propagate when the strain energy release rate $G$ exceeds a critical value $G_{c}$. Here I follow (2) and begin by noting that in the classical Griffith theory of fracture, the critical energy release rate $G$ is related to the energy required to create new fracture surface area. Fracturing is then said to be brittle, or to have small-scale yielding, if ductile flow is localized to a vanishingly small region near the crack tip. If this condition is met, then one may proceed with an analysis of linear elastic fracture mechanics (LEFM). Analytically, the condition of small scale yielding permits the use of elasticity solutions for the state of stress near a fracture. This state of stress has an amplitude given by an inverse square root dependence on radial distance from the crack tip and is proportional to a value called the stress intensity factor $K$. Under LEFM, the energy release rate is then proportional to the square of the stress intensity factor $G=K^{2} / E$, for Young's modulus $E$. The fracture criterion may then be expressed as $K=K_{c}$, where $K_{c}$ is called the fracture toughness, a material parameter that characterizes brittle fracture. Typical values of the fracture toughness of ice are measured (3) to be near $100 \mathrm{kPa} \mathrm{m}^{1 / 2}$.

Assuming small scale yielding for now, ice shelf rift propagation is expected to occur when

$$
\left(\sigma_{c}-p_{w}\right) \sqrt{\pi L}=K_{c}
$$

where $L$ is the rift half length. I have introduced the subscripted $c$ to denote that $\sigma$ has reached the critical value to cause propagation. In writing Equation 1, I have neglected any dependence 
of the stress intensity factor on the ice shelf geometry due, for example, to interaction with an ice front. I note that this balance between water pressure, ice pressure, and deviatoric stresses is essentially the same as that considered by (4), with the only differences being that I consider horizontal rather than vertical propagation and that I later generalize this condition beyond small scale yielding.

Equation 1 is a depth-dependent fracture criterion that evaluates whether horizontal propagation will occur at a given depth. The depth in the ice shelf that requires the highest stress to fracture is the depth with the lowest water pressure and therefore the largest compressive stress. This occurs at the water line $z=0$, where there is zero water pressure. At this depth, the fracture criterion is,

$$
\left(2 \tau_{c}-\rho g s\right) \sqrt{\pi L}=K_{c}
$$

or

$$
\tau_{c}=\frac{K_{c}}{2 \sqrt{\pi L}}+\frac{\rho g s}{2}
$$

This relation shows that a necessary condition for rift propagation is that the rift normal deviatoric stress exceeds the weight of ice above the water line. When this condition is met then the term in parentheses is positive, indicating crack extension. I consider the following example of the dynamics resulting from this fracture criterion. Suppose an ice shelf is about $250 \mathrm{~m}$ thick so that $\rho g s \approx 240 \mathrm{kPa}$. Then the resolved deviatoric stress acting normal to the rift must exceed $120 \mathrm{kPa}$ in order for propagation to proceed. For typical ice shelf rift lengths on the order of several to tens or hundreds of $\mathrm{km}, K_{c} / \sqrt{\pi L}$ is in the range of 200 to $2000 \mathrm{~Pa}$, suggesting that the rift propagation is mostly stress-limited rather than fracture toughness-limited. This observation therefore suggests that an approximate rift propagation criterion is simply that

$$
\tau_{c} \geq \rho g s / 2,
$$

which is Equation 1 in the main text (in the main text I drop the subscripted $c$ for notational sim- 
plicity). Classical studies of ice elastic fracture have also neglected the ice fracture toughness (5). I note that the specific justification for this approximation is that $K_{c} / \sqrt{\pi L} \ll 2 \tau_{c}-\rho g s$. I note that Equation 3 is equivalent to the value of Equation B.1 in (6) if crevasses are assumed to propagate through the ice thickness.

\subsection{Lateral variations in ice shelf properties}

Lateral variations in ice thicknesses and deviatoric stresses modify the above analysis. I consider a rift of length $2 L$ with varying $\sigma(x)$. The endpoints of the rift are at $x=-L$ and $x=L$, and the stress intensity factor for the rift tip located at $x=L$ is (2),

$$
K=\frac{1}{\sqrt{\pi L}} \int_{-L}^{+L} \sigma(\xi) \frac{\sqrt{L+\xi}}{\sqrt{L-\xi}} d \xi
$$

If the lateral variations in the stress $\sigma(x)$ are approximated as linear, then $\sigma(x)=\sigma_{L}[1+$ $\alpha(L-x)]$ where $\sigma_{L}=2 \tau(L)+\rho g s(L)$ is the value of $\sigma(x)$ at $x=L$. Fracture then occurs when

$$
\tau_{c}>\frac{K_{c}}{\sqrt{\pi L}\left(1+\frac{\alpha L}{2}\right)}+\frac{\rho g s(L)}{2}
$$

Even for lateral stress variations that are large by glaciological standards (e.g., $\alpha=0.1$ ), the fracture toughness term is negligible compared to the overburden term. Based on this analysis, I consider Equation 2 to be an adequate rift propagation criterion for typical glaciological conditions. I have already begun to examine coupled numerical solutions involving Equation 4. A full description of this work, however, is well beyond the scope of current manuscript.

\subsection{Transition to ductile yielding}

The above analysis assumed a brittle ice rheology. I now consider the possibility for more widespread ductile flow during rift propagation. The main result of this section is that ductile flow rather than brittle fracture occurs in ice shelves at depths greater than about $250 \mathrm{~m}$ in meteoric ice and depths greater than about $25 \mathrm{~m}$ in marine ice. 
As described above, the region in front of a rift tip experiences high stresses. If ice were perfectly elastic these stresses would be infinite. In real ice, stresses are finite and are capped at the yield strength in tension $\sigma_{y}$. I employ the classical model of a cohesive zone as a region of length $R$ in front of the rift tip over which the ice transitions from being undeformed to being completely broken. I begin by following Rubin (7) to quantify the effect of ice overburden pressure $\rho g z$ on the cohesive zone size $R$.

Following the above analysis, the stress intensity factor is, $\left(\sigma-p_{w}\right) \sqrt{\pi(L+R)}$. The degree to which water pressure acts in the cohesive zone is essential (7). Within the cohesive zone, ice in tension is expected to exhibit transgranular clevage and stretching (8). Given typical ice shelf temperature profiles (9), if any water is able to percolate into the cold, partially fractured cohesive zone it will quickly freeze. For this reason, I assume that no water pressure acts in the cohesive zone. Water pressure, in contrast therefore has contribution $-p_{w} \sqrt{8 R / \pi}$. The resistive stress acting in the cohesive zone has contribution, $\sigma_{y} \sqrt{8 R / \pi}$.

The length of the cohesive zone $R$ is then set by assuming zero total stress intensity factor,

$$
\left(\sigma-p_{w}\right) \sqrt{\pi(L+R)}+\left(p_{w}-\sigma_{y}\right) \sqrt{8 R / \pi}=0
$$

where the second term expresses the assumption that no water pressure acts in the cohesive zone. I solve for the plastic zone length $R$ as a function of depth $z$,

$$
\frac{R}{L+R} \approx \frac{R}{L}=\frac{\pi^{2}}{8}\left(\frac{\sigma-p_{w}}{\sigma_{y}-p_{w}}\right)^{2}
$$

Which shows that as the water pressure $p_{w}$ approaches the yield stress, the assumption of small scale yielding is invalidated because $R / L$ becomes arbitrary large, prompting Equation 2 in the main text.

Several previous studies have invoked high fracture toughness in suture zones as being the mechanism by which these features stabilize rift propagation. Here, I argue that this statement is not technically correct and that stabilization in suture zones occurs because of the transition 
to ductile flow. The following analysis, however, shows that the brittle-ductile transition results in an apparent fracture toughness with values much greater than those measured in laboratory experiments. Assuming that a ice completely breaks at a crack tip opening displacement $\delta \approx$ $10 \mu \mathrm{m}(10)$, the apparent fracture toughness as would be measured at the tip of the cohesive zone is (7),

$$
K_{\text {apparent }}=\sqrt{\frac{2 G}{\pi(1-\nu)} \frac{\sigma_{y}^{2}}{\sigma_{y}-p} \delta} .
$$

As the condition $\sigma_{y}=p$ occurs quite shallow in low strength marine ice, Equation 5 explains why it would appear as if suture zones had high fracture toughness when in fact their ability to arrest fracture is due to their ductility.

\section{Analysis of published geophysical data sets}

I use the 2014 imagery of the MODIS-derived Mosaic of Antarctica $(11,12)$ to create an update to the rifts analyzed by (13). The histogram of all ice shelf thicknesses is calculated from downsampled (5 km) Bedmap2 data (14).

I calculate the time until thinning to the brittle-ductile transition thickness using previously published melt rates $(15)$ and ice thickness $(14,16)$. In the case of the Larsen B ice shelf I use ice thickness from ERS-1 (17). Table 1 in the main text includes all ice shelves listed in (15) that account for greater than $1 \%$ of total ice shelf area and have $\partial h / \partial t$ uncertainty less than the expected value, i.e., where the sign of the thickness change is known within observational uncertainty.

I reference the grounding line calculated by (18) and strain rate maps as calculated by (19). Maps were created with the Antarctic Mapping Toolbox (20). 


\section{References}

1. D. R. MacAyeal, Journal of Geophysical Research: Solid Earth 94, 4071 (1989).

2. H. Tada, P. C. Paris, G. R. Irwin, Handbook, Del Research Corporation (1973).

3. M. Rist, P. Sammonds, H. Oerter, C. Doake, Journal of Geophysical Research: Solid Earth 107 (2002).

4. C. Van der Veen, Cold Regions Science and Technology 27, 31 (1998).

5. J. Nye, Journal of Glaciology 2, 512 (1955).

6. D. Pollard, R. M. DeConto, R. B. Alley, Earth and Planetary Science Letters 412, 112 (2015).

7. A. M. Rubin, Journal of Geophysical Research: Solid Earth 98, 15919 (1993).

8. E. M. Schulson, P. Duval, et al., Creep and fracture of ice, vol. 1 (Cambridge University Press Cambridge, 2009).

9. K. M. Cuffey, W. S. B. Paterson, The physics of glaciers (Academic Press, 2010).

10. J. Dempsey, D. Cole, S. Wang, Phil. Trans. R. Soc. A 376, 20170346 (2018).

11. T. Scambos, T. Haran, M. Fahnestock, T. Painter, J. Bohlander, Remote Sensing of Environment 111, 242 (2007).

12. M. K. J. B. M. F. T. P. Haran, T., T. Scambos (2018). National Snow and Ice Data Center.

13. C. Walker, J. Bassis, H. Fricker, R. Czerwinski, Journal of Geophysical Research: Earth Surface 118, 2354 (2013). 
14. P. Fretwell, et al. (2013).

15. E. Rignot, S. Jacobs, J. Mouginot, B. Scheuchl, Science 341, 266 (2013).

16. S. Chuter, J. Bamber, Geophysical Research Letters 42, 10 (2015).

17. J. Bamber, Boulder, Cororado: National Snow and Ice Data Center (2000).

18. E. Rignot, J. Mouginot, B. Scheuchl, Geophysical Research Letters 38 (2011).

19. K. Alley, et al., Journal of Glaciology pp. 1-12 (2018).

20. C. A. Greene, D. E. Gwyther, D. D. Blankenship, Computers \& Geosciences 104, 151 (2017). 